\title{
Effect of polymers on rheological properties of waxy bitumens
}

\section{Efecto de los polímeros sobre las propiedades reológicas de los betunes céreos}

Julide Oner (Main and Corresponding Author)

Department of Civil Engineering, Engineering Faculty, Usak University

Bir Eylul Campus, 64000, Usak (Turkey)

julide.oner@usak.edu.tr

\section{Burak Sengoz}

Department of Civil Engineering, Engineering Faculty, Dokuz Eylul University

Tinaztepe Campus, 35600, Izmir (Turkey)

burak.sengoz@usak.edu.tr

Manuscript Code: 1018

Date of Acceptance/Reception: 24.05.2018/12.03.2017

DOI: 10.7764/RDLC.17.2.279

\begin{abstract}
The definition of bitumen wax has been formulated to facilitate the distinction between harmful wax and less harmful or non-harmful. Since exact behaviour of waxes within bitumens is not completely determined and the absence of cooperative study related to modification of bitumens involving different amounts of waxes, the values found in the study are thought to be useful in determining which content of wax and type of polymer would be better for the needs of petroleum refineries in different countries. The scope of this study is to minimize the negative effects of waxes within bitumens obtained from different sources. For this purpose, modified bitumen samples were prepared by using different types of polymers such as elastomers, plastomers and polyethylene groups. Following the determination of the contents of wax by Differential Scanning Calorimetry and TS EN 12606-1, rheological properties of waxy bitumens and polymer modified bitumens (PMB) were evaluated using dynamic shear rheometer tests. The intermediate temperature performance levels of PMB were also determined by fatigue parameters. Besides, rutting performance of PMB was evaluated using Zero Shear Viscosity and Multiple Stress Creep Recovery tests.
\end{abstract}

Key words: Wax, dynamic shear rheometer, fatigue parameter, zero shear viscosity, multiple stress creep recovery.

Resumen

La definición de cera bituminosa se ha formulado para facilitar la distinción entre cera nociva y menos nociva o no. Dado que el comportamiento exacto de las ceras en betunes no está completamente determinado y la ausencia de un estudio cooperativo relacionado con la modificación de betunes que involucran diferentes cantidades de ceras, los valores encontrados en el estudio se consideran útiles para determinar qué contenido de cera y tipo de polímero ser mejor para las necesidades de las refinerías de petróleo en diferentes países. El objetivo de este estudio es minimizar los efectos negativos de las ceras en los betunes obtenidos de diferentes fuentes. Para este propósito, se prepararon muestras de betún modificado usando diferentes tipos de polímeros tales como elastómeros, plastómeros y grupos de polietileno. Tras la determinación del contenido de cera por calorimetría de barrido diferencial y TS EN 12606-1, se evaluaron las propiedades reológicas de los betunes céreos y los betunes modificados con polímeros (PMB) utilizando pruebas de reómetro de cizallamiento dinámico. Los niveles intermedios de rendimiento de temperatura de PMB también fueron determinados por los parámetros de fatiga. Además, el rendimiento de celo de PMB se evaluó usando pruebas de Cero Cizalladura de Esfuerzo y Recuperación de Estrés Múltiple.

Palabras clave: Cera, reómetro de corte dinámico, parámetro de fatiga, viscosidad de cizallamiento cero, recuperación de fluencia por estrés multiple.

Introduction

Almost all bitumen is obtained from crude oil by refining process but only certain crude oils contain good quality bitumen for asphalt pavement (Lyne, Wallqvist, \& Birgisson, 2013). Naphthenic-base crude oils often give a large amount of bitumen that may be in good quality, while paraffinic crude oils may give bitumen of good quality or yield bitumen that are not suitable for asphalt pavement (Edwards, \& Redelius, 2003).

Wax in bitumen has been referred as petroleum wax and is obtained from refining of paraffinic crude oils. The effects of wax on the properties of bitumen depend on the following factors: the source, chemical composition and rheology of the bitumen. There is a lack of literature reviews related to the effect of waxes on rheology and conventional properties of bitumen.

Waxes in bitumen are divided into two general categories such as macro-crystalline and micro-crystalline wax (Edwards, 2009). Macro-crystalline wax also known as paraffin which crystallizes in large flat plates or needles. It refers to the group of $n$-alkanes with few or no branches $\left(C_{20}-C_{40}\right)$ (Soenen et al., 2013). The melting point of macro- 
crystalline paraffin waxes are around $50-70^{\circ} \mathrm{C}$ (Lu, Langton, Olofsson, \& Redelius, 2005; Lu \& Redelius, 2007). On the other hand, micro-crystalline wax is collected in the bitumen fraction after the distillation process and mainly consists of naphthens and iso-paraffins as well as crystallizes as small microscopic needles. A micro-crystalline petroleum wax is characterized also by a less distinct melting area and its high average molecular weight giving higher viscosity compared to macro crystalline paraffin wax (Das, Kringos, Wallqvist, \& Birgisson, 2013; Musser \& Kilpatrick, 1998).

Based on literature, the high content of wax affects the properties of bitumen in different ways. The low melting point of wax decreases resistance of asphalt mixtures against rutting at high temperatures (Lu \& Redelius, 2006). Physical hardening, poor ductility and poor bitumen adhesion can be listed as the outcomes caused by the high content of wax (Edwards\& Redelius, 2003).

The term "polymer" merely refers to very large molecules made by many chemically reacting small molecules to produce long chains (Becker, Mendez, \& Rodriguez, 2001). Polymer modified bitumen (PMB) has been developed by asphalt industry to fulfill the needs for making better pavements that exhibit better performance under loads due to high traffic applications. The use of PMB has become a very important part of pavement construction due to its superior performance, including less ageing, enhanced rutting resistance and lower fatigue cracking properties (Dubois, Mehta, \& Nolan, 2014). The most commonly used polymer for bitumen modification is the styrenebutadiene-styrene (SBS) followed by other polymers such as ethylene vinyl acetate (EVA) and polyethylene (PE) (Sengoz \& Isikyakar, 2008).

SBS block copolymers are classified as elastomers that increase the elasticity of bitumen. Elastomers derive their strength and elasticity from a physical cross-linking of the molecules into a three-dimensional network (Shirini \& Imaninasab, 2016). This is achieved by the agglomeration of the polystyrene end-blocks into separate domains, providing the physical cross-links for a three-dimensional polybutadiene or polyisoprene rubbery matrix. It is the polystyrene end-blocks that impart strength to the polymer and the mid-block that gives the material its exceptional elasticity (Whiteoak \& Read, 2003). When the polymer is added to the hot bitumen, the bitumen immediately starts to penetrate the polymer particles causing the styrene domains of the polymer to become solvated and swollen. Once this has occurred, the level of shear exerted on the swollen particle is critical if a satisfactory dispersion is to be achieved within a realistic blending time. Thus, high shear mixers are required to adequately disperse thermoplastic elastomers into the bitumen (Whiteoak \& Read, 2003).

EVA based polymers are classified as plastomer that modify bitumen by forming a tough, rigid, three-dimensional network to resist deformation. EVA copolymer is an irregular shaped thermoplastic material produced by copolymerization of ethylene and vinyl acetate. The properties of copolymer vary as the content of vinyl acetate increases (Gorkem, 2014). Overall characteristics of the EVA copolymer are controlled by their molecular weight and the ratio of vinyl acetate. EVA copolymers can be easily dispersed in bitumen and provide a good compatibility (Gorkem, 2014). The addition of EVA to the bitumen mix is not only used to improve the performance of pavement. It is also used in significant quantities in cold weather applications. EVA improves the workability of mixture because of its sensitivity against shear force and ability to be used with softer bitumen (Woolley, 1986).

The polyethylene (PE) is a type of product normally not used as additive to bitumen, generally showing a congealing point of $92-100^{\circ} \mathrm{C}$; it has been used in plastics and polishes, as thickener for lubricating oils and petrolatum and as paraffin wax improver/upgrader (Edwards, 2009). PE is manufactured from natural gas derived feedstock by two basic polymerization processes. The low pressure polymerization process results in linear polymer chains with short side branches. The high pressure polymerization process results in polymer chains with more highly developed side branches. PE modified bitumen is less expensive as well as shows more resistance to ultraviolet aging and rutting (Zhu, Birgisson, \& Kringos, 2014).

Although the many significant researches which have been carried out related to the PMB in road applications, more studies should be undertaken on the compatibility and in the interaction between polymers and the different sources bitumens according to the needs of refineries in different countries. The main purpose behind this study is to minimize the negative effects of waxes within bitumens obtained from different sources. For this purpose; following the determination of wax contents of five types waxy bitumens obtained from two different countries, bitumen samples were modified by recommended content of three different polymers (SBS polymer at concentration of $3.2 \%$ by weight of the bitumen, EVA polymer at concentration of $1.4 \%$ by weight of the bitumen and PE polymer at concentration of $1.5 \%$ by weight of the bitumen). The effects of adding polymers into waxy bitumens have been acquired through rheological test methods. The upper critical temperatures used in performance grading (PG) system have been determined for each bitumen sample using $\mathrm{G}^{*} / \sin \delta$ results from the dynamic shear rheometer (DSR) test (Soudani, Cerezo, \& Haddani, 2016). The effects of loading and temperature on the performance of the samples have 
been evaluated using $\mathrm{G}^{*} / \sin \delta$ results from low $(0.01 \mathrm{~Hz})$ and high frequencies $(10 \mathrm{~Hz})$ loadings at five different temperatures $\left(40^{\circ} \mathrm{C}-80^{\circ} \mathrm{C}\right)$. The intermediate temperature performance levels of $\mathrm{PMB}$ were also determined by fatigue parameters. Rutting performance of PMB samples has been evaluated using the zero shear viscosity (ZSV) and multiple stress creep recovery (MSCR) test performed in the creep mode. The results have been compared with base bitumen and PMB samples.

Metodology

\section{Materials}

Five bitumens from two different sources (Turkey and Russia) were used in this study. The bitumen samples are identified as Bit TR and Bit R respectively. The general description of samples together with penetration grades are depicted in Table 1.

\begin{tabular}{lccc}
\multicolumn{4}{c}{ Table 1. The general description of samples. } \\
\hline Source of Bitumens & Abbreviation & Sample No & Penetration Grades \\
\hline Turkey & Bit TR & Bit-TR1 & $50 / 70$ \\
& & Bit-TR2 & $40 / 60$ \\
Russia & Bit R & Bit-R1 & $60 / 90$ \\
& & Bit-R2 & $60 / 90$ \\
& & Bit-R3 & $70 / 100$ \\
\hline
\end{tabular}

Since the bitumens are originated from different sources, their wax contents are different. Bit-TR1 was manufactured from crude oil deposited in the east part of Turkey. Russia (Bit-R1, Bit-R2 and Bit-R3) bitumens and Bit-TR2 were produced by the blending of crude oil from various sources by a manufacturer in Western Siberia and Middle Eastern countries respectively. Besides, a limited amount of air blowing was used to manufacture Bit-R1 during the refining process.

Among the polymer asphalt modifying agents, SBS styrene-butadiene-styrene) originally developed by LG Chemical Cooperation is widely used in the majority of the asphalt bitumen industry and probably the most appropriate elastomeric type of polymer for asphalt modification. Luprene LG $^{\circledR} 501$ is a thermoelastoplastic material which consists of linear styrene-butadiene-styrene block copolymer, highly viscous, oil-free. Luprene LG $^{\circledR} 501$ is used as bitumen modifier for improvement of the quality of PMBs used mainly for road pavements. The concentration of SBS used was $3.2 \%$ by weight of the bitumen. Appropriate amount of bitumen $(500 \mathrm{~g})$ in $500 \mathrm{ml}$ graduated beaker was heated in the stove at $170^{\circ} \mathrm{C}$ to become fluid enough and then placed under the laboratory type mixer (Sengoz \& Isikyakar, 2008). SBS pallets were gradually added to the bitumen. The mixer was set at 800 rpm during 3 hours (mixing period). The mixture's temperature was maintained at $160 \pm 5^{\circ} \mathrm{C}$ during the mixing process (Sengoz \& Isikyakar, 2008; Sengoz, Bagayogo, Oner, \& Topal, 2017; Topal et al., 2018).

The EVA (ethylene vinyl acetate) polymer used was Elvaloy ${ }^{\circledR} 4170$ (1.4\% by weight of the bitumen) supplied in pellet form by DuPont, USA. Elvaloy ${ }^{\circledR} 4170$, which contains butylacrylate $20 \%$ by weight and glycidyl methacrylate $9 \%$ by weight, have proved themselves as good plastomeric type modifiers that reduce permanent deformation and thermal cracking. When bitumen is modified with Elvaloy ${ }^{\circledR} 4170$, the polymer amount has to be chosen carefully because an excessive quantity can cause the formation of an insoluble bitumen gel. The modifications were done using laboratory type mixer set at 200 rpm during 2 hours (Oner, \& Sengoz, 2017; Sengoz, Bagayogo, Oner, \& Topal, 2017). During the mixing process, the temperature of the mixture was kept at $180 \pm 5^{\circ} \mathrm{C}$.

The used PE (polyethylene)) was Titan ${ }^{\circledR} 7686$ in white pellet form obtained from Honeywell company, USA. Titan ${ }^{\circledR}$ 7686 is created through the polymerization of ethylene. Titan ${ }^{\circledR} 7686$ has low molecular weight and semi-crystaline structure. Addition of PE significantly improves the mechanical properties of bitumens. The concentration of PE used was $1.5 \%$ by weight of the bitumen. The mixer was set at $800 \mathrm{rpm}$ during 1 hour (mixing period). The mixture's temperature was maintained at $150 \pm 5^{\circ} \mathrm{C}$ during the mixing process.

\section{Test methods}

Determination of the paraffin wax content based on European Standard Method EN 12606-1. The European Standard EN 12606-1 is based on DIN 52015, a German method that is performed for determining the paraffin wax 
content of bitumen samples (Baldino et al., 2012; European Standard EN 12606-1, 2007). The system includes a distilling system, an electric cooler, a thermo-regulator and compressor refrigeration.

Test procedure is performed on two portions for each of $25 \mathrm{~g}$ bitumen samples. The distillate from bitumen is obtained by a specified distillation process. The distillation unit is consisted of a distillation flask, a laboratory burner and erlenmeyer flask used as distillation receiver. The distillation takes place at very high temperatures (up to over $500^{\circ} \mathrm{C}$ ) at which cracking of molecules may occur (Lu \& Redelius, 2006). On the second portion of the test procedure; the waxy distillate is dissolved in ether/ethanol $(50 / 50, \mathrm{~V} / \mathrm{V})$ solvent and crystallized at $-20^{\circ} \mathrm{C}$. The crystallized wax is obtained by filtration (European Standard EN 12606-1, 2007).

Differential Scanning Calorimetry (DSC). The crystallization or melting of waxes in bitumen causes an energy change. Both heating and cooling cycles can be utilized to investigate the presence of wax fraction in bitumen. The exothermic and endothermic effects during the cooling and heating scan generally represent the wax crystallization and wax melting respectively. Differential Scanning Calorimetry (DSC) method has been utilized to register thermal effects of waxes in bitumen through the cooling-heating cycles (ASTM D4419-90, 2015).

In this study, thermal characterization was performed using DSC; Perkin Elmer-Diamond. Approximately 15 mg of bitumen samples is placed in an aluminium pan and sealed under nitrogen atmosphere. The bitumen sample is heated to $+120^{\circ} \mathrm{C}$ and then cooled at $7^{\circ} \mathrm{C} / \mathrm{min}$ to $-50^{\circ} \mathrm{C}$, followed by heating to $+120^{\circ} \mathrm{C}$ at the same rate. DSC procedure is also used to determine wax content in bitumen. The DSC wax content of bitumen is calculated from an endothermic peak during the heating scan. For the calculation of percentage of wax in the bitumen, a constant melting enthalpy value of $121 \mathrm{~J} / \mathrm{g}$ is used as a reference (Lu, Kalman, \& Redelius, 2008). A typical DSC diagram is presented in Figure 1.

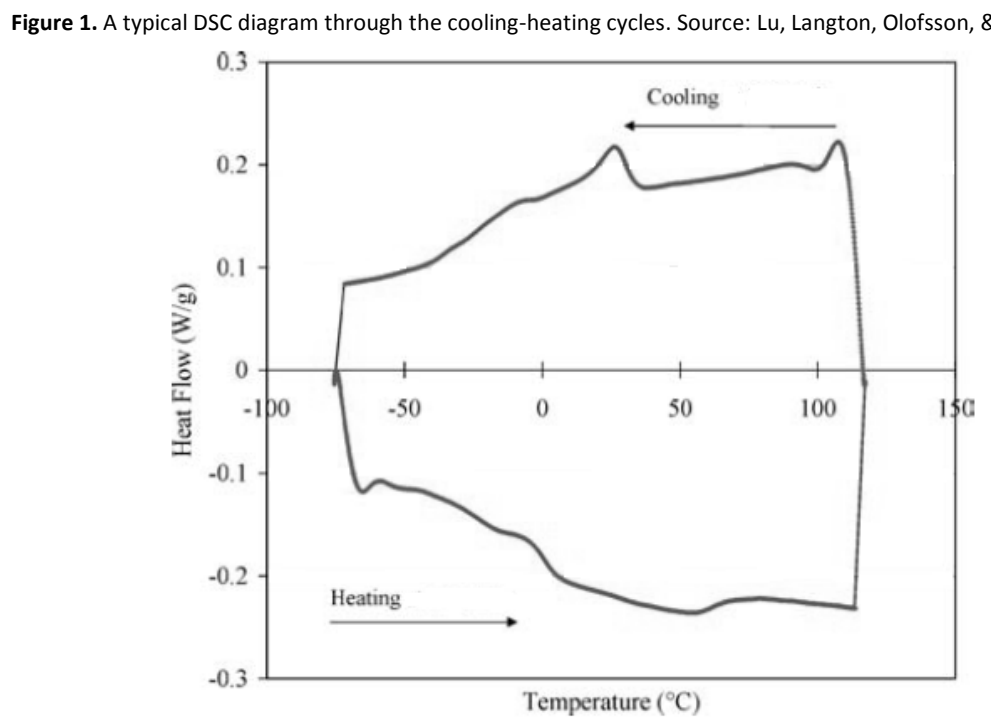

Glass transition temperature, wax crystallization starting temperature and melting out temperature are also determined by DSC results. The glass transition temperature $\left(\mathrm{Tg}_{\mathrm{g}}\right)$ which is defined as the half-vitrification temperature is midpoint of the transition region (Edwards, Tasdemir, \& Isacsson, 2006). The glass transition temperature obtained from the heating scan is more repeatable and easier to obtain in comparison to the cooling scan. From DSC, bitumen exhibits a kind of phase transition on cooling from high temperature and heating from the low temperature. The first transition has been considered as crystallization starting temperature $\left(T_{i c}\right)$ in cooling cycle. Besides, the new phase transition has occurred during the heating cycle. There is an endothermic reaction which is interpreted as the melting of the wax. Wax melting out temperature defined as $\mathrm{T}_{\mathrm{fm}}$ is the end point of wax melting in bitumen (Oner \& Sengoz, 2017).

Rheological test methods. The dynamic shear rheometer (DSR) is used to describe the viscous and elastic behaviour of asphalt bitumen at medium to high temperatures (Santagata, Baglieri, Tsantilis, \& Dalmazzo, 2012). This characterization is used in the Superpave PG asphalt bitumen specification. The basic DSR test uses a thin bitumen sample sandwiched between two circular plates. The lower plate is fixed while the upper plate oscillates back and forth across the sample at $10 \mathrm{rad} / \mathrm{sec}(1.59 \mathrm{~Hz})$ (or any other set frequency) to create a shearing action. DSR tests are conducted on unaged, RTFOT aged and PAV (pressure aging vessel) aged bitumen samples (ASTM D 2872-12, 2012; ASTM D6521-05, 2005; Santagata, Baglieri, Tsantilis, \& Dalmazzo, 2012; Soudani, Cerezo, \& Haddani, 2016). 
The determination of complex rheological properties of bitumen is currently possible with the utilization of DS). Parameters most commonly tested in DSR include the bitumen complex shear modulus (G*) and phase angle ( $\delta$ ), tested in various temperature and frequency ranges. The complex shear modulus ( $\left.\mathrm{G}^{*}\right)$ can be considered the sample's total resistance to deformation when repeatedly sheared, while the phase angle $(\delta)$, is the lag between the applied shear stress and the resulting shear strain. $\mathrm{G}^{*}$ and $\delta$ are used as predictors of rutting and fatigue behaviours. Fatigue properties of bitumen can be evaluated by the fatigue factor at intermediate temperatures. The fatigue behaviour was investigated by applying continuous oscillatory shear loadings with using DSR. Early in pavement life rutting is the main concern, while later in pavement life fatigue cracking becomes the major concern. $G * / \sin \delta$ is described as rutting indicating parameter and $\mathrm{G}^{*} . \sin \delta$ as fatigue cracking indicating factor (Asphalt Institute, 2001).

The Superpave ${ }^{\circledR}$ specification parameter, $G^{*} / \sin \delta$, was identified as the term to be used for high temperature performance grading of paving asphalts in rating the bitumens for their rutting resistance (Xiao, Hou, Amirkhanian, \& $\mathrm{Kim}, 2016)$. Although used for many years as a rutting parameter, it has been demonstrated that the relationship between $\mathrm{G}^{*} / \sin \delta$ and rutting is poor. This term was found to be inadequate in describing the rutting performance of bitumens (Subhy, 2017).

Zero Shear Viscosity (ZSV) is the viscosity measured in shear deformation at a shear rate approaching to zero. This parameter is an indicator for rutting related bitumen characteristics. It has been observed by researchers in the recent years, that the rutting parameter $\mathrm{G}^{*} / \sin \delta$ is not very effective or failed to predict the rutting performance of bitumen (De Visscher, Soenen, Vanelstraete, \& Redelius, 2004). The determination of ZSV in this study is performed by the application of creep test using DSR. Static creep is defined as the slow deformation of a material measured under a constant stress. In the static creep test, a fixed shear stress is applied to the sample and the resultant strain is monitored for a predetermined amount of time (Xiao, Hou, Amirkhanian, \& Kim, 2016; Gungor, \& Saglik, 2012). All of the samples were short-term aged using a RTFOT procedure. The ZSV of the samples have been predicted by application of creep test at $60^{\circ} \mathrm{C}$ (CEN/TS 15325, 2008). The test geometry for the creep tests consisted of $25 \mathrm{~mm}$ parallel plates and the gap between the plates was $1 \mathrm{~mm}$. The stress level was $10 \mathrm{~Pa}$ for bitumen samples and each creep test was continued for 30 minutes.

Developments led to the existence of Multiple Stress Creep and Recovery (MSCR) test (Dubois, Mehta, \& Nolan, 2014). MSCR test was run on RTFOT aged samples in accordance to ASTM D7405-08 using the dynamic shear rheometer (ASTM D7405-08, 2008; Shenoy, 2008). The ASTM standard procedure establishes the use of two stress levels (0.1 and $3.2 \mathrm{kPa}$ ), $1 \mathrm{~s}$ creep time, $9 \mathrm{~s}$ recovery time, and 10 creep-recovery cycles at each stress level. Anton Paar DSR with its parallel-plate geometry loading device and a control and data acquisition system were utilized for conducting the MSCR test in the present study. Specimens were tested using a $25 \mathrm{~mm}$ parallel plates and with $1 \mathrm{~mm}$ gap setting at temperature of $60^{\circ} \mathrm{C}$ and at a stress of 100 and $3200 \mathrm{~Pa}$. The tests were performed at the selected temperature using a constant stress creep of 1 second duration and a relaxation period of 9 seconds, for ten cycles at each stress level. Percent recoverable and non-recoverable components of creep compliance were determined at the end of 10 cycles (Shenoy, 2008).

Results and discussions

\section{Determination of wax content in bitumens through EN 12606-1 and DSC}

Calculation of the wax content is based on the following formula based on European Standard Method EN $12606-1$. Wax content is calculated as:

$P=\frac{m_{1} * m_{W}}{m_{b} * m_{2}} * 100$

where $P(m \%)$ is wax content, $m_{b}(g)$ is the mass of specimen, $m_{1}(g)$ is the total mass of distillated oil, $m_{2}(g)$ is the mass of distillated oil for wax extraction and $m_{w}(g)$ is the mass of wax extracted (European Standard EN 12606-1, 2007).

The crystallization or melting of waxes in bitumens involves energy change that can be easily determined by DSC. The results of the EN 12606-1 and DSC measurements are summarized in Table 2 in terms of wax content, crystallization starting temperature, wax melted out temperature and glass transition temperature (Oner, \& Sengoz, 2017). 


\begin{tabular}{|c|c|c|c|c|c|c|}
\hline & Bitumen & Bit-TR1 & Bit-TR2 & Bit-R1 & Bit-R2 & Bit-R3 \\
\hline & Sources & Turkey & Turkey & Russia & Russia & Russia \\
\hline & $\begin{array}{l}\text { Wax content by EN 12606-1 } \\
(\%)\end{array}$ & 0.8 & 2.70 & 2.0 & 2.1 & 2.3 \\
\hline & Wax content by DSC (\%) & 2.61 & 3.52 & 4.81 & 3.93 & 4.04 \\
\hline \multirow{3}{*}{ 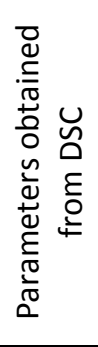 } & $\begin{array}{l}\text { Crystallization starting } \\
\text { temperature }-\mathrm{T}_{\text {ic }} \\
\text { by } \operatorname{DSC}\left({ }^{\circ} \mathrm{C}\right)\end{array}$ & 39.11 & 45.93 & 50.22 & 47.95 & 55.40 \\
\hline & $\begin{array}{l}\text { Melting out temperature - } \\
T_{f m} \\
\text { by DSC }\left({ }^{\circ} \mathrm{C}\right)\end{array}$ & 65.97 & 84 & 80 & 65 & 83 \\
\hline & $\begin{array}{l}\text { Glass transition } \\
\text { temperature }-\mathrm{T}_{\mathrm{g}} \text { by } \mathrm{DSC}\left({ }^{\circ} \mathrm{C}\right)\end{array}$ & -7.05 & -15.16 & -16.08 & -21.65 & -20.56 \\
\hline
\end{tabular}

As indicated in Table 2, bitumen samples from different sources exhibit different wax content based on DSC and EN 12606-1 methods. It is clearly seen that, EN 12606-1 method gives much lower values in wax contents as compared with DSC. It is believed that the high temperature (up to over $500{ }^{\circ} \mathrm{C}$ ) distillation step in EN $12606-1$ method may destroy the molecular structure of waxes (thermal cracking) (Edwards, 2009). The resulting smaller paraffin molecules could be soluble in ether/ethanol and do not crystallize in the solvent at the specified low temperature $\left(-20{ }^{\circ} \mathrm{C}\right)$, leading to lower apparent wax content. These might be reasons for the low wax contents as determined by the EN 12606-1 method. The difference in wax content between the two tests may also be due to the solubility of wax in the bitumen providing unlike crystallisation/melting response in DSC. In fact, all the available methods used for determining wax content in bitumen only demonstrate relative results. Bitumen sample from Turkey (Bit-TR1) contains the lowest amount of wax compared to other bitumen samples according to EN 12606-1 and DSC methods (Oner \& Sengoz, 2017).

DSC has been widely applied to characterize the thermodynamics properties of bituminous materials. In cooling cycle, crystallization occurs at different temperatures which is interpreted as wax crystallization starting temperature ( $T_{i c}$ ). The transition continues down to the glass transition temperatures. In heating cycle, there is an endothermic reaction which is interpreted as melting of the wax. Wax melting out temperatures of bitumens is defined as $T_{f m}$. The temperature at which all wax is completely melted is considerably higher than the start of crystallization. This is due to the super cooling effect at cooling cycle. Effects of low temperature on bitumen properties are typically evidenced by the glass transition temperature $\left(T_{g}\right)$. When temperature is lower than $T_{g}$, bitumens are glassy, hard and brittle, whereas for the temperature higher than $T_{g}$ visco-elastic properties are exhibited. The transition continues down to the glass transition which can be seen at the lowest temperature $\left(-21.65^{\circ} \mathrm{C}\right)$ for Bit-R2. Consequently; Bit-R2, which includes average value of wax percentage, with the lowest value of $\mathrm{T}_{\mathrm{g}}$ may have more resistance to low temperature cracking compared to other sources bitumens at a specific low temperature (Oner, \& Sengoz, 2017).

\section{Rheological test results}

This section includes the results of rheological tests applied on all of the bitumen samples obtained by the different sources. The results have been presented into three groups of Dynamic Shear Rheometer (DSR) test results, Zero Shear Viscosity (ZSV) test results, Multiple Stress Creep Recovery (MSCR) test results. The coefficient of variation (which is calculated as the ratio of standard deviation to mean value) related to rheological bitumen tests such as $\mathrm{G}^{*} / \sin \delta, \mathrm{G}^{*} . \sin \delta, \mathrm{ZSV}$ and MSCR varies between $0.59 \%$ and $1.85 \%$ indicating a reasonable consistency. The calculated variances indicate that the determined results of rheological tests vary in acceptable ranges.

Dynamic Shear Rheometer (DSR) test results. In order to determine upper critical temperature used in performance grading (PG) system, un-aged and RTFOT aged specimens of bitumens containing different content of wax were subjected to oscillating shear in the DSR at the frequency of $10 \mathrm{rad} / \mathrm{s}(1.59 \mathrm{~Hz})$. The temperature cycles were set to start at $52^{\circ} \mathrm{C}$ for un-aged and $64^{\circ} \mathrm{C}$ for RTFOT aged samples an run up in $6^{\circ} \mathrm{C}$ increments. The upper critical temperatures (Tcrit) used in PG system were determined for each sample using the obtained G*/sin $\delta$ results and DSR specifications for PG bitumen. In PG system, the upper critical temperature is the temperature at which $G^{*} / \sin \delta=1.0$ $\mathrm{kPa}$ for un-aged bitumen, and $\mathrm{G}^{*} / \sin \delta=2.2 \mathrm{kPa}$ for RTFOT aged bitumen (Asphalt Institute, 2001). The upper critical temperatures (Tcrit) for each sample modified with SBS, EVA and PE are presented in Table 3, Table 4 and Table 5 respectively. 


\begin{tabular}{|c|c|c|c|c|}
\hline \multirow[b]{2}{*}{ Bitumen } & \multicolumn{3}{|c|}{ DSR, G*/sin $\delta(\mathrm{Pa})$} & \multirow{2}{*}{$\begin{array}{c} \\
\text { Upper } \\
\text { Performance } \\
\text { Grades }\end{array}$} \\
\hline & $\begin{array}{c}\text { Temperature } \\
\left({ }^{\circ} \mathrm{C}\right)\end{array}$ & Non-aged & Aged & \\
\hline \multirow[t]{5}{*}{ Bit-TR1 } & 52 & $1.25 \mathrm{E}+04$ & & 70 \\
\hline & 58 & 5918 & & \\
\hline & 64 & 2820 & 5816 & \\
\hline & 70 & 1384 & 2868 & \\
\hline & 76 & 702 & 1462 & \\
\hline Bit-TR1 & 52 & $6.33 E+04$ & & 82 \\
\hline+ & 58 & $3.38 \mathrm{E}+04$ & & \\
\hline \multirow[t]{5}{*}{ SBS } & 64 & $1.71 \mathrm{E}+04$ & $3.23 E+04$ & \\
\hline & 70 & 8963 & $1.81 \mathrm{E}+04$ & \\
\hline & 76 & 4609 & 9980 & \\
\hline & 82 & 1471 & 3345 & \\
\hline & 88 & 943 & 1850 & \\
\hline \multirow[t]{4}{*}{ Bit-R1 } & 52 & 7006 & & 64 \\
\hline & 58 & 3392 & & \\
\hline & 64 & 1628 & 4009 & \\
\hline & 70 & 797.5 & 1903 & \\
\hline Bit-R1 & 52 & $2.92 \mathrm{E}+04$ & & 82 \\
\hline+ & 58 & $1.60 \mathrm{E}+04$ & & \\
\hline \multirow[t]{5}{*}{ SBS } & 64 & 8498 & $1.72 E+04$ & \\
\hline & 70 & 4523 & 9643 & \\
\hline & 76 & 2408 & 5164 & \\
\hline & 82 & 1334 & 2801 & \\
\hline & 88 & 739.5 & 1550 & \\
\hline \multirow[t]{4}{*}{ Bit-R2 } & 52 & 6785 & & 64 \\
\hline & 58 & 3241 & & \\
\hline & 64 & 1551 & 3650 & \\
\hline & 70 & 769.7 & 1775 & \\
\hline Bit-R2 & 52 & $2.42 \mathrm{E}+04$ & & 82 \\
\hline+ & 58 & $1.29 \mathrm{E}+04$ & & \\
\hline \multirow[t]{5}{*}{ SBS } & 64 & 6418 & $1.59 E+04$ & \\
\hline & 70 & 3209 & 8635 & \\
\hline & 76 & 1615 & 4651 & \\
\hline & 82 & 1058.6 & 2390 & \\
\hline & 88 & 725.1 & 1321 & \\
\hline \multirow[t]{4}{*}{ Bit-R3 } & 52 & 5165 & & 64 \\
\hline & 58 & 2431 & & \\
\hline & 64 & 1147 & 3346 & \\
\hline & 70 & 556.7 & 1648 & \\
\hline Bit-R3 & 52 & $1.66 \mathrm{E}+04$ & & 76 \\
\hline+ & 58 & 9079 & & \\
\hline \multirow[t]{4}{*}{ SBS } & 64 & 4784 & $1.28 \mathrm{E}+04$ & \\
\hline & 70 & 2508 & 6834 & \\
\hline & 76 & 1344 & 3487 & \\
\hline & 82 & 710.3 & 1853 & \\
\hline \multirow[t]{4}{*}{ Bit-TR2 } & 52 & 8047 & & 64 \\
\hline & 58 & 3493 & & \\
\hline & 64 & 1592 & 3356 & \\
\hline & 70 & 779 & 1493 & \\
\hline Bit-TR2 & 52 & $2.03 \mathrm{E}+04$ & & 70 \\
\hline+ & 58 & 9202 & & \\
\hline \multirow[t]{3}{*}{ SBS } & 64 & 4159 & 8064 & \\
\hline & 70 & 1915 & 3888 & \\
\hline & 76 & 943.6 & 1931 & \\
\hline
\end{tabular}


Table 4. Determination of PG upper critical temperatures for EVA modification.

\begin{tabular}{|c|c|c|c|c|}
\hline & \multirow{2}{*}{\multicolumn{3}{|c|}{$\mathrm{DSR}, \mathrm{G}^{*} / \sin \delta(\mathrm{Pa})$}} & \multirow{3}{*}{$\begin{array}{c} \\
\text { Upper } \\
\text { Performance } \\
\text { Grades }\end{array}$} \\
\hline & & & & \\
\hline Bitumen & $\begin{array}{c}\text { Temperature } \\
\left({ }^{\circ} \mathrm{C}\right)\end{array}$ & Non-aged & Aged & \\
\hline \multirow[t]{5}{*}{ Bit-TR1 } & 52 & $1.25 \mathrm{E}+04$ & & 70 \\
\hline & 58 & 5918 & & \\
\hline & 64 & 2820 & 5816 & \\
\hline & 70 & 1384 & 2868 & \\
\hline & 76 & 702 & 1462 & \\
\hline Bit-TR1 & 52 & $2.90 \mathrm{E}+04$ & & 88 \\
\hline+ & 58 & $1.55 \mathrm{E}+04$ & & \\
\hline \multirow{5}{*}{ EVA } & 64 & 7550 & $2.55 E+04$ & \\
\hline & 70 & 4478 & $1.41 \mathrm{E}+04$ & \\
\hline & 76 & 3087 & 7832 & \\
\hline & 82 & 2491 & 4358 & \\
\hline & 88 & 1369 & 2412 & \\
\hline \multirow[t]{4}{*}{ Bit-R1 } & 52 & 7006 & & 64 \\
\hline & 58 & 3392 & & \\
\hline & 64 & 1628 & 4009 & \\
\hline & 70 & 797.5 & 1903 & \\
\hline Bit-R1 & 52 & $2.00 \mathrm{E}+04$ & & 88 \\
\hline+ & 58 & $1.19 \mathrm{E}+04$ & & \\
\hline \multirow{5}{*}{ EVA } & 64 & 7156 & $1.40 \mathrm{E}+04$ & \\
\hline & 70 & 4445 & 8606 & \\
\hline & 76 & 3200 & 5393 & \\
\hline & 82 & 2038 & 3484 & \\
\hline & 88 & 1388 & 2308 & \\
\hline \multirow[t]{4}{*}{ Bit-R2 } & 52 & 6785 & & 64 \\
\hline & 58 & 3241 & & \\
\hline & 64 & 1551 & 3650 & \\
\hline & 70 & 769.7 & 1775 & \\
\hline Bit-R2 & 52 & $1.69 \mathrm{E}+04$ & & 82 \\
\hline+ & 58 & 9708 & & \\
\hline \multirow{5}{*}{ EVA } & 64 & 5402 & $1.11 \mathrm{E}+04$ & \\
\hline & 70 & 2910 & 6548 & \\
\hline & 76 & 2014 & 3959 & \\
\hline & 82 & 1245 & 2418 & \\
\hline & 88 & 803.5 & 1535 & \\
\hline \multirow[t]{4}{*}{ Bit-R3 } & 52 & 5165 & & 64 \\
\hline & 58 & 2431 & & \\
\hline & 64 & 1147 & 3346 & \\
\hline & 70 & 556.7 & 1648 & \\
\hline Bit-R3 & 52 & 9344 & & 76 \\
\hline+ & 58 & 5125 & & \\
\hline \multirow{4}{*}{ EVA } & 64 & 3027 & 6773 & \\
\hline & 70 & 2024 & 4009 & \\
\hline & 76 & 1275 & 2473 & \\
\hline & 82 & 836.5 & 1548 & \\
\hline \multirow[t]{4}{*}{ Bit-TR2 } & 52 & 8047 & & 64 \\
\hline & 58 & 3493 & & \\
\hline & 64 & 1592 & 3356 & \\
\hline & 70 & 779 & 1493 & \\
\hline Bit-TR2 & 52 & $1.16 \mathrm{E}+04$ & & 70 \\
\hline+ & 58 & 5441 & & \\
\hline \multirow{3}{*}{ EVA } & 64 & 2644 & 4280 & \\
\hline & 70 & 1342 & 2186 & \\
\hline & 76 & 713.2 & 1056 & \\
\hline
\end{tabular}




\begin{tabular}{|c|c|c|c|c|}
\hline \multirow[b]{2}{*}{ Bitumen } & \multirow[b]{2}{*}{$\begin{array}{c}\text { Temperature } \\
\left({ }^{\circ} \mathrm{C}\right)\end{array}$} & \multicolumn{2}{|c|}{ DSR, G*/sin $\delta(P a)$} & \multirow{2}{*}{$\begin{array}{c}\text { Upper } \\
\text { Performance } \\
\text { Grades }\end{array}$} \\
\hline & & Non-aged & Aged & \\
\hline \multirow[t]{5}{*}{ Bit-TR1 } & 52 & $1.25 \mathrm{E}+04$ & & 70 \\
\hline & 58 & 5918 & & \\
\hline & 64 & 2820 & 5816 & \\
\hline & 70 & 1384 & 2868 & \\
\hline & 76 & 702 & 1462 & \\
\hline Bit-TR1 & 52 & $2.29 E+04$ & & 76 \\
\hline+ & 58 & $1.12 \mathrm{E}+04$ & & \\
\hline \multirow{5}{*}{ PE } & 64 & 6362 & $2.15 E+04$ & \\
\hline & 70 & 3458 & $1.08 \mathrm{E}+04$ & \\
\hline & 76 & 1764 & 6534 & \\
\hline & 82 & 932 & 3500 & \\
\hline & 88 & & 1964 & \\
\hline \multirow[t]{4}{*}{ Bit-R1 } & 52 & 7006 & & 64 \\
\hline & 58 & 3392 & & \\
\hline & 64 & 1628 & 4009 & \\
\hline & 70 & 797.5 & 1903 & \\
\hline Bit-R1 & 52 & $1.37 \mathrm{E}+04$ & & 76 \\
\hline+ & 58 & 7088 & & \\
\hline \multirow{4}{*}{ PE } & 64 & 3697 & $1.28 \mathrm{E}+04$ & \\
\hline & 70 & 1962 & 6664 & \\
\hline & 76 & 1054 & 3525 & \\
\hline & 82 & 570.2 & 1882 & \\
\hline \multirow[t]{4}{*}{ Bit-R2 } & 52 & 6785 & & 64 \\
\hline & 58 & 3241 & & \\
\hline & 64 & 1551 & 3650 & \\
\hline & 70 & 769.7 & 1775 & \\
\hline Bit-R2 & 52 & $1.59 \mathrm{E}+04$ & & 76 \\
\hline+ & 58 & 8028 & & \\
\hline \multirow{4}{*}{$\begin{array}{l}+ \\
\mathrm{PE}\end{array}$} & 64 & 3938 & 9232 & \\
\hline & 70 & 2085 & 4736 & \\
\hline & 76 & 1103 & 2472 & \\
\hline & 82 & 601.6 & 1296 & \\
\hline \multirow[t]{4}{*}{ Bit-R3 } & 52 & 5165 & & 64 \\
\hline & 58 & 2431 & & \\
\hline & 64 & 1147 & 3346 & \\
\hline & 70 & 556.7 & 1648 & \\
\hline Bit-R3 & 52 & 8379 & & 70 \\
\hline+ & 58 & 4255 & & \\
\hline \multirow{3}{*}{$\mathrm{PE}$} & 64 & 2234 & 5606 & \\
\hline & 70 & 1195 & 2930 & \\
\hline & 76 & 660.5 & 1537 & \\
\hline \multirow[t]{4}{*}{ Bit-TR2 } & 52 & 8047 & & 64 \\
\hline & 58 & 3493 & & \\
\hline & 64 & 1592 & 3356 & \\
\hline & 70 & 779 & 1493 & \\
\hline Bit-TR2 & 52 & $1.33 \mathrm{E}+04$ & & 70 \\
\hline+ & 58 & 6137 & & \\
\hline \multirow{3}{*}{ PE } & 64 & 2853 & 5201 & \\
\hline & 70 & 1426 & 2408 & \\
\hline & 76 & 750.1 & 1167 & \\
\hline
\end{tabular}

As presented in Table 3-5, modifications of base bitumens containing different wax contents with SBS, EVA and PE increases the PG upper critical temperature $\left(T_{\text {crit }}\right)$. Higher $T_{\text {crit }}$ value is an indicator of higher resistance to permanent deformation. On the other hand, EVA polymer modified samples depicted the highest critical temperatures. Bit-TR2 containing the highest wax content has the lowest PG upper critical temperature for all modifications. There is no significant variation for $T_{\text {crit }}$ values of Bit-TR2 with modification process. However, the addition of polymers into bitumens containing low wax content changes $T_{\text {crit }}$ value of the modified bitumen appreciably. 
All of the modified RTFOT aged samples including different contents of wax were subjected to oscillating shear in the DSR at low $(0.01 \mathrm{~Hz})$ and high $(10 \mathrm{~Hz})$ frequency levels at five different temperature cycles ranging from $40^{\circ} \mathrm{C}$ to $80^{\circ} \mathrm{C}$ with $10^{\circ} \mathrm{C}$ increment. The variation of $\mathrm{G}^{*} / \sin \delta$ (rutting parameter) values of the modified samples with SBS, EVA and $\mathrm{PE}$ at low and high frequencies are presented in Figure 2-7.

Figure 2. $\mathrm{G} * / \sin \delta$ values for SBS modified bitumens at $0.01 \mathrm{~Hz}$.

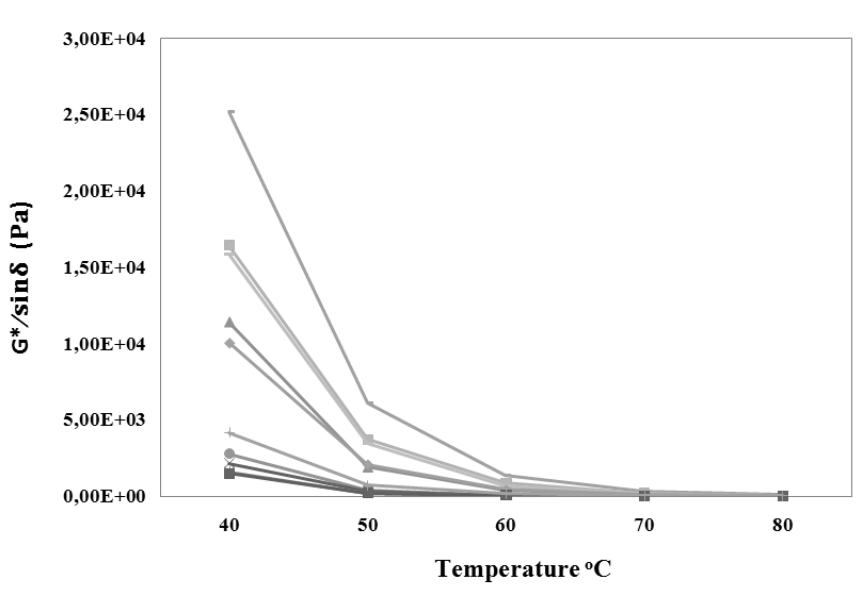

$\underline{0.01 \mathrm{~Hz}}$
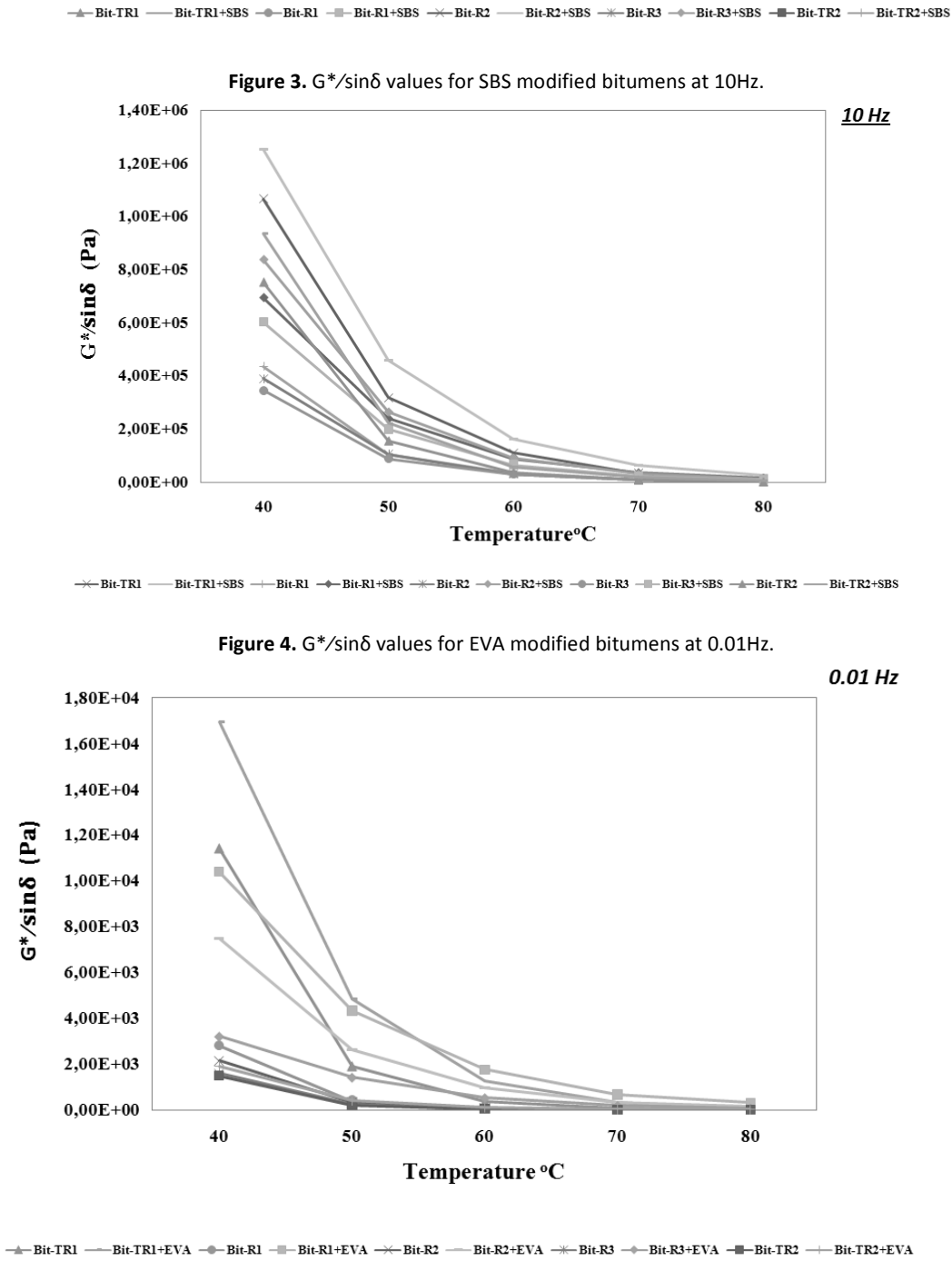

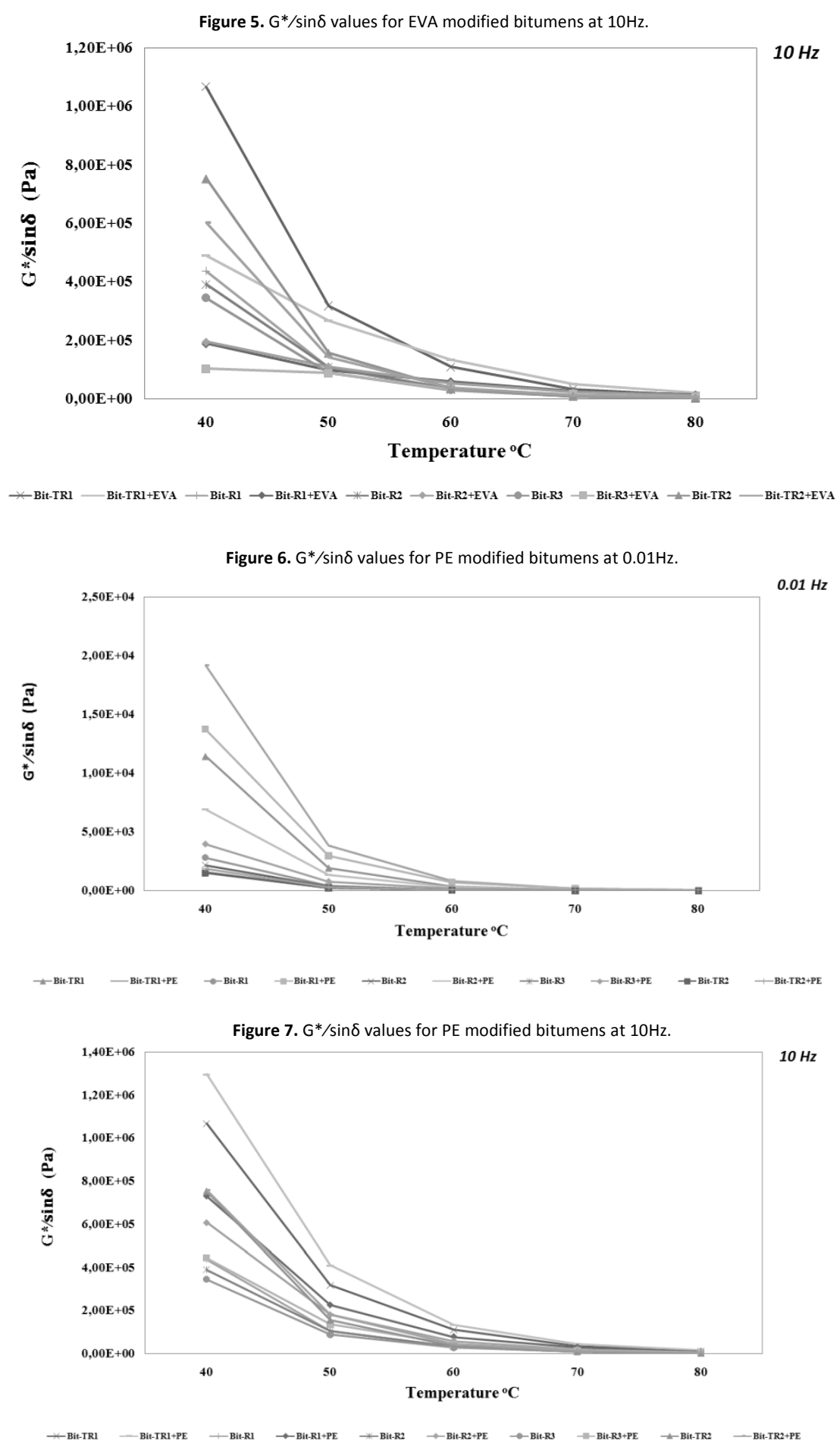

As presented Figure 2-7; regarding all of bitumen samples, $G * /$ sin $\delta$ values increase with decrease in temperature at both frequencies. An increment in $\mathrm{G}^{*} / \mathrm{sin} \delta$ value indicates higher performance against rutting. Besides, as expected $\mathrm{G} * / \sin \delta$ values increase with an increase in frequency for all of the bitumen samples. This is due to the rheological behaviour of the bitumen since bitumen under shorter loading times (high frequency level) exhibit elastic behaviour (Whiteoak, \& Read, 2003).

As can be seen in Figure 2-7, unmodified sample containing the highest wax content depicted the lowest G*/sin $\delta$ value at both high and low frequencies and at all temperatures. Besides; all of the polymer modified bitumen samples depicted higher $\mathrm{G}^{*} / \mathrm{sin} \delta$ value than the base bitumens at both high and low frequencies and at all temperatures. However, SBS and PE modified samples exhibited greater $\mathrm{G}^{*} / \mathrm{sin} \delta$ value as compared to EVA modified samples especially at high frequency level and at intermediate temperatures $\left(40^{\circ} \mathrm{C}\right.$ and $\left.50^{\circ} \mathrm{C}\right)$. 
Hence based on $\mathrm{G}^{*} / \mathrm{sin} \delta$ values, it is found that modification of waxy bitumen and with SBS or PE resulted in improved rutting resistance performance at both low and high frequencies. Besides it is also found that modification of waxy bitumen with SBS has more pronounced effect against rutting compared to the modification with EVA polymer.

Temperature sweep test is performed under the strain controlled mode at a frequency of $10 \mathrm{rad} / \mathrm{s}(1.59 \mathrm{~Hz}$.). The temperature cycles were set to start at $40^{\circ} \mathrm{C}$ within the PAV aged samples a run up in $3^{\circ} \mathrm{C}$ decrements. During the test procedure, an $8 \mathrm{~mm}$ diameter plate with a $2 \mathrm{~mm}$ gap between parallel plates was used for each PAV aged bitumen sample. There is a limiting maximum stiffness at the intermediate temperature to mitigate fatigue cracking. G*.sin $\delta$ values of PAV aged bitumen samples does not exceed $5000 \mathrm{kPa}$ and low values of these parameters are considered good indicators of fatigue cracking resistance (Asphalt Institute, 2003). Variation of the fatigue parameters (G*.sin $\delta$ ) for PAV aged SBS, EVA and PE modified bitumens containing different contents of wax at different intermediate temperatures are illustrated in Figure 8, Figure 9 and Figure 10 respectively.
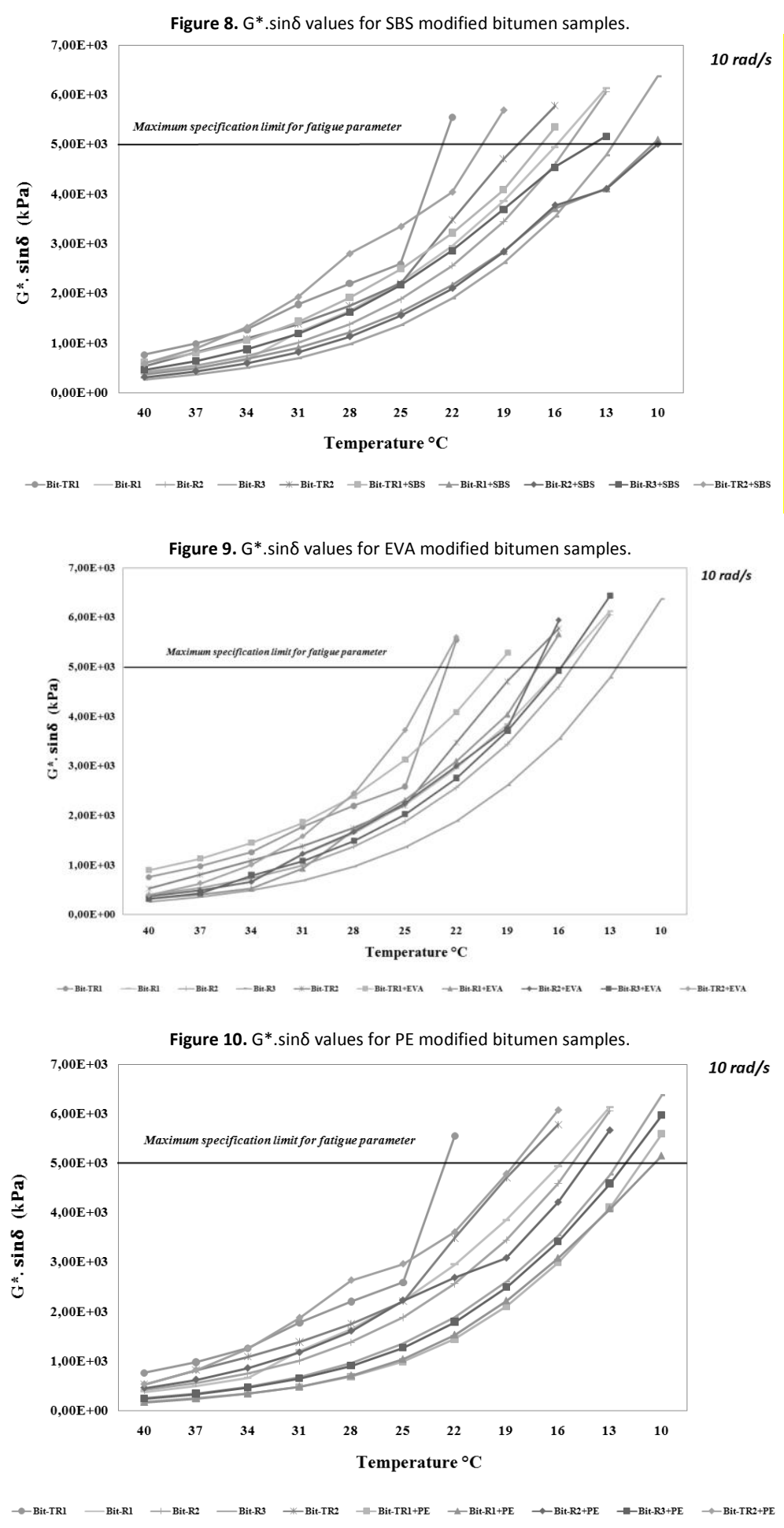
As depicted Figure 8-10, regarding all of bitumen samples, G*.sin $\delta$ values increase with decrease in temperature at 10 $\mathrm{rad} / \mathrm{s}$. Owing to the aging, the lower $\mathrm{G}^{*} . \sin \delta$ value indicates less shearing energy loss and better ability of the fatigue resistance (Ali, Mashaan, \& Karim, 2013). Bit-TR1 samples containing the lowest wax contents exhibit the highest $\mathrm{G}^{*} . \sin \delta$ value at all intermediate temperatures. Higher $\mathrm{G}^{*}$.sin $\delta$ values is not preferable since the samples with higher $\mathrm{G}^{*} . \sin \delta$ values exhibit fatigue cracking.

The addition of SBS and EVA polymers into the base bitumens containing different contents of wax did not make any significant effect on the fatigue cracking properties on the samples. However, the limitation of $5000 \mathrm{kPa}$ value is reached at Bit-TR1+PE, Bit-R1+PE, Bit-R2+PE and Bit-R3+PE which occur at the test temperature $13{ }^{\circ} \mathrm{C}$ as well as Bit$\mathrm{TR} 2+\mathrm{PE}$ meets with specification limit at the temperature $19^{\circ} \mathrm{C}$.

Hence, modification process with PE depicted slightly improved fatigue cracking properties of waxy bitumens compared to SBS and EVA modifications that expresses the ability of the material to resist cracking at intermediate temperatures.

Zero Shear Viscosity (ZSV) test results. The zero shear viscosity (ZSV) results of all of the modified bitumen samples including different content of wax, determined by the utilization of DSR machine applied in creep mode are illustrated in Figure 11.

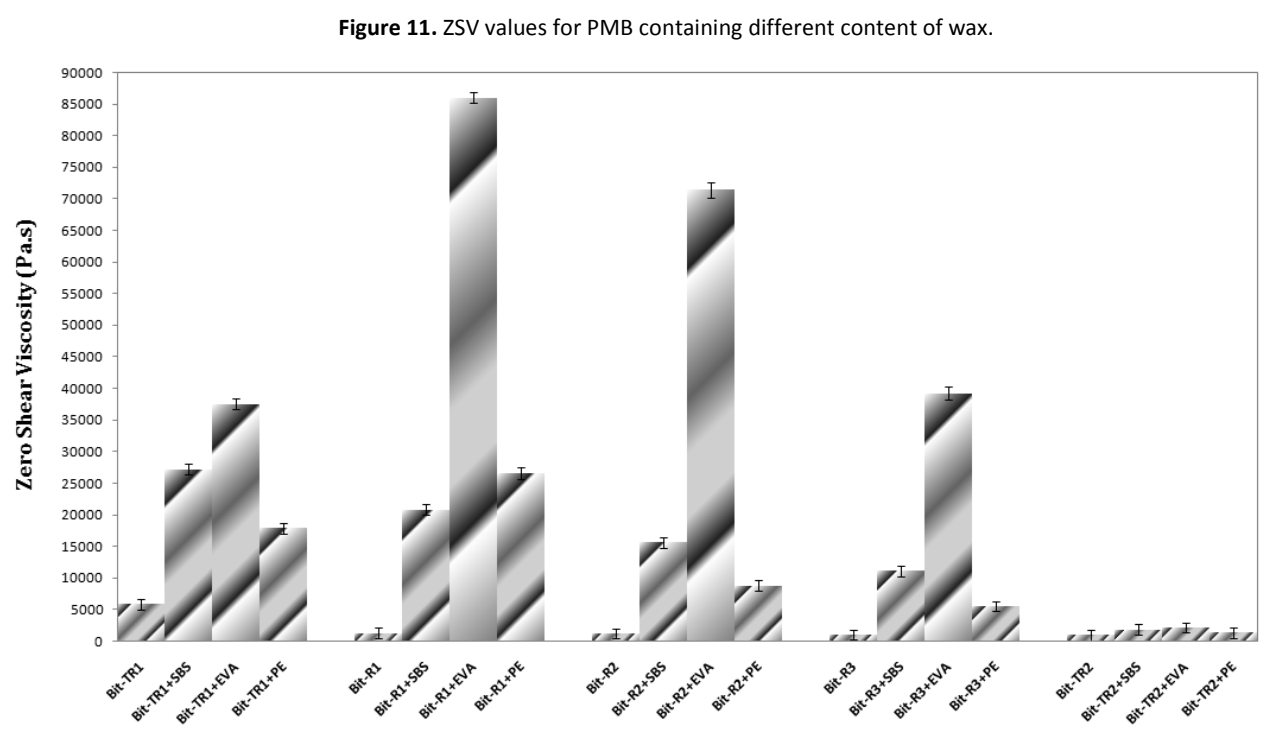

As illustrated in Figure 11, samples containing low amount of wax yield higher ZSV value than other base bitumen samples. A higher ZSV value indicates higher resistance to permanent deformation under long-term loading. The ZSV values decrease with increasing in the content of wax in the unmodified (base) bitumen samples. Besides all of the modified bitumen samples exhibit higher ZSV values than the base bitumen samples. The increment is more obvious at $1.4 \%$ concentration of EVA into bitumens containing different wax content compared to SBS and PE modification processes. Modification with EVA yields the peak ZSV value in Bit-R1 samples.

Multiple Stress Creep and Recovery (MSCR) test results. The percent recoveries (R), the non recoverable compliance $(\mathrm{Jnr})$ at two different stress level of $100 \mathrm{~Pa}$ and $3200 \mathrm{~Pa}$ and stress sensitivity as well as the percent differences in non recoverable compliances (Jnr-diff) of the bitumens are presented in Table 6.

As presented in Table 6; Bit-TR2 samples containing the highest content of wax have the lowest recovery at any of the stress levels which indicates that Bit-TR2 perform less rutting resistance than other unmodified samples. This can be due to the low stiffness and the low elastic behaviour of Bit-TR2 samples. The addition of polymer into bitumen samples containing different wax content depicted higher recovery at any of the stress levels. Higher percent recoveries indicate that the bitumen can recover a higher portion of its total strain at the end of each loadingunloading cycle, which is favourable to the resistance of the material to rutting. On the other hand; EVA modified bitumen samples exhibited the highest recovery values in comparison with SBS and PE modified bitumen samples. Similar conclusion may also be evaluated for the non-recoverable creep compliance $\left(\mathrm{J}_{\mathrm{nr}}\right)$ values. Lower $\mathrm{J}_{\mathrm{nr}}$ values indicates lower susceptibility of bituminous material to rutting. 
Table 6. Average values of the MSCR test parameters calculated from the test data.

\begin{tabular}{|c|c|c|c|c|c|c|}
\hline Bitumen & $\begin{array}{c}\mathrm{R} @ 100 \mathrm{~Pa} \\
(\%)\end{array}$ & $\begin{array}{c}\mathrm{R} @ 3200 \mathrm{~Pa} \\
(\%)\end{array}$ & $\begin{array}{c}\text { Jnr @100 Pa } \\
(1 / \mathrm{kPa})\end{array}$ & $\begin{array}{c}\text { Jnr @3200 Pa } \\
(1 / \mathrm{kPa})\end{array}$ & $\begin{array}{c}\text { Jnr diff. } \\
(\%)\end{array}$ & $\begin{array}{c}\text { Stress } \\
\text { Sensitivity }\end{array}$ \\
\hline Bit-TR1 & 35.029 & 29.862 & 0.211 & 0.231 & 9.522 & 0.095 \\
\hline Bit-TR1+SBS & 58.398 & 58.297 & 0.051 & 0.051 & 1.306 & 0.031 \\
\hline Bit-TR1+EVA & 69.355 & 68.951 & 0.047 & 0.047 & 0.942 & 0.009 \\
\hline Bit-TR1+PE & 56.081 & 51.368 & 0.075 & 0.084 & 12.386 & 0.124 \\
\hline Bit-R1 & 24.774 & 10.080 & 0.826 & 1.069 & 29.401 & 0.294 \\
\hline Bit-R1+SBS & 70.225 & 62.027 & 0.066 & 0.086 & 28.203 & 0.282 \\
\hline Bit-R1+EVA & 90.850 & 92.598 & 0.018 & 0.016 & 7.094 & 0.071 \\
\hline Bit-R1+PE & 70.452 & 57.544 & 0.079 & 0.118 & 48.897 & 0.489 \\
\hline Bit-R2 & 23.339 & 9.509 & 0.849 & 1.094 & 28.649 & 0.286 \\
\hline Bit-R2+SBS & 60.630 & 56.366 & 0.084 & 0.096 & 13.274 & 0.132 \\
\hline Bit-R2+EVA & 88.485 & 86.906 & 0.032 & 0.036 & 12.628 & 0.127 \\
\hline Bit-R2+PE & 55.853 & 33.710 & 0.183 & 0.309 & 68.999 & 0.689 \\
\hline Bit-R3 & 17.455 & 5.991 & 1.164 & 1.474 & 26.615 & 0.266 \\
\hline Bit-R3+SBS & 58.314 & 52.723 & 0.129 & 0.149 & 16.362 & 0.163 \\
\hline Bit-R3+EVA & 86.232 & 85.821 & 0.073 & 0.072 & 0.578 & 0.005 \\
\hline Bit-R3+PE & 48.533 & 20.028 & 0.357 & 0.660 & 65.161 & 0.651 \\
\hline Bit-TR2 & 5.148 & 2.688 & 1.305 & 1.404 & 7.596 & 0.076 \\
\hline Bit-TR2+SBS & 24.443 & 17.589 & 0.557 & 0.669 & 20.192 & 0.202 \\
\hline Bit-TR2+EVA & 42.517 & 32.925 & 0.516 & 0.592 & 14.537 & 0.145 \\
\hline Bit-TR2+PE & 12.154 & 4.992 & 0.865 & 0.990 & 14.758 & 0.148 \\
\hline
\end{tabular}

The percent differences in non-recoverable compliances (Jnr-diff) and the stress sensibility of the samples are also presented in Table 6 . This percent difference is a measure of the sensitivity of the bitumen to the increase in the stress level; therefore lower values are associated with a less stress sensitive material. The Jnr-diff and the stress sensitivity are low for EVA modified bitumen samples which indicates that the sample can be considered to be less stress sensitive with a $3200 \mathrm{~Pa}$ within the all bitumen samples. 
The scope of the research is to reduce the negative effects of waxes within bitumens containing various wax contents. For this purpose, modified bitumen samples were prepared by using different types of polymer additives. The values found in the study can be considered as useful parameters in determining which content of wax and type of polymer would be better for the needs of refineries in different countries. The following conclusions can be withdrawn from the extensive laboratory research.

EN 12606-1 method gives much lower values in the wax content as compared to DSC. DSC method may be recommended for determining wax content since the high temperature distillation step in EN 12606-1 method destroys the molecular structure of waxes.

According to high temperature performance test results; it can be evaluated that modifications of base bitumens containing different wax contents increases PG upper critical temperature with SBS, EVA and PE. Modification with EVA increases more the PG upper critical temperature of both Bit-TR1 and Bit-R1 than modification with SBS and PE.

The frequency sweep test results indicated that modification of bitumens containing different wax contents had an influence on the bitumen rheology. The DSR test results indicated that rutting parameter increases as the temperature decreases at both low and high frequency. Furthermore, when the frequency increases, the rutting parameter also increases. This derives from the rheological behavior of bitumen since bitumens exhibit an elastic behavior under sorter loading periods. Besides, it is found that modification of waxy bitumen and with SBS or PE resulted in improved rutting resistance performance at both low and high frequencies. Nevertheless it is also found that modification of waxy bitumen with SBS improves more the performance of the materials against rutting than modification with EVA.

The fatigue parameter test results obtained by DSR showed that the fatigue increases when the temperature decreases. Under the PAV aging condition, the temperature of bitumens of high wax content is lower than that for bitumen with low wax content at the time the stiffness value of $\mathrm{G}^{*} . \sin \delta$ reaches $5000 \mathrm{kPa}$. Modification process with PE depicted slightly improved fatigue cracking properties of waxy bitumens compared to SBS and EVA modifications that expresses the ability of the material to resist cracking at intermediate temperatures.

In the light of findings from ZSV values, it is indicated that samples containing low amount of wax yield higher ZSV value than other base bitumen samples. This can be due to high viscosity and low wax content that give the mixture stability at service temperature. Besides all of the modified bitumen samples show a higher ZSV value than the base bitumen samples. Modification process improves the rutting resistance and the improvement is more pronounced with EVA polymer. A higher ZSV value indicates higher resistance to permanent deformation under long-term loading.

In light of findings from MSCR test results, the addition of polymer into bitumens containing different wax content depicted higher recovery and lower $J_{n r}$ values at any of the stress levels. EVA modified bitumen samples exhibited the highest recovery and the lowest $J_{n r}$ values in comparison within the polymer modified bitumen samples. In terms of the asphalt mixture, bitumens with lower $J_{n r}$ values and/or higher recovery values will less contribute to the accumulation of unrecovered strain in the asphalt layer. Based on the rheological test results, G*/sin $\delta$ and ZSV values have a good correlation with the MSCR parameters.

Hence, modification process with EVA and PE can be recommended to improve rutting and fatigue cracking properties of waxy bitumens respectively.

In this study, the rheological bitumen tests have been performed on different sources bitumen samples involving different types of polymers in order to reduce negative effects of waxes. It is recommended to conduct Bending Beam Rheometer (BBR) test on polymer modified bitumen samples to evaluate their performance at lower temperatures.

The authors are thankful to the ABZ-1 Group Company, Saint Petersburg, RUSSIA for their support for performing laboratory tests. 
Ali, A.H., Mashaan, N.S., \& Karim, M.R. (2013). Investigations of physical and rheological properties of aged rubberised bitumen. Advances in Materials Science and Engineering, 2013, 1-8. DOI: 10.1155/2013/239036

Asphalt Institute (2001). SUPERPAVE mix design series no: 2. Asphalt Institute Research Center, Lexington, USA.

ASTM D2872-12 (2012). Standard test method for effect of heat and air on a moving film of asphalt (Rolling Thin-Film Oven Test). West Conshohocken PA, USA.

ASTM D4419-90 (2015). Standard test method for measurement of transition temperatures of petroleum waxes by differential scanning calorimetry (DSC). West Conshohocken PA, USA.

ASTM D6521-05 (2005). Standard practice for accelerated aging of asphalt binder using a pressurized aging vessel (PAV). West Conshohocken PA, USA.

ASTM D7405-08 (2008). Standard test method for multiple stress creep and recovery (MSCR) of asphalt binder using a dynamic shear rheometer. West Conshohocken PA, USA.

Baldino, N., Gabriele, D., Rossi, C.O., Seta, L., Lupi, F.R., \& Caputo, P. (2012). Low temperature rheology of polyphosphoric acid (PPA) added bitumen. Construction and Building Materials, 36, 592-596. DOI: 10.1016/j.conbuildmat.2012.06.011

Becker, Y., Mendez, M.P., \& Rodriguez, Y. (2001). Polymer modified asphalt. Vision Tecnologica, 9(1), 39-50.

CEN TS 15325 (2008). Bitumen and bituminous binders: Determination of zero shear viscosity (ZSV) using a shear stress rheometer in creep mode. European Committee for Standardization, EU.

Das, P.K., Kringos, N., Wallqvist, V., \& Birgisson, B. (2013). Micromechanical investigation of phase separation in bitumen by combining AFM with DSC results. Road Materials and Pavement Design, 14, 25-37. DOI: 10.1080/14680629.2013.774744

De Visscher, J., Soenen, H., Vanelstraete, A., \& Redelius, P.A. (2004). Comparison of the zero shear viscosity from oscillation tests and the repeated creep test. Proceedings of Euroasphalt \& Eurobitume Congress, Vienna, AUSTRIA.

Dubois, E., Mehta,D., \& Nolan, A. (2014). Correlation between multiple stress creep recovery (MSCR) results and polymer modification of binder. Construction and Building Materials, 65, 184-190. DOI: 10.1016/j.conbuildmat.2014.04.111

Edwards, Y. (2009). Influence of waxes on bitumen and asphalt concrete mixture performance. Road Materials and Pavement Design, 10(2), 313335. DOI: $10.1080 / 14680629.2009 .9690197$

Edwards, Y., Tasdemir, Y., \& Isacsson, U. (2006). Effects of commercial waxes on asphalt concrete mixtures performance at low and medium temperatures. Cold Regions Science and Technology, 45(1), 31-41. DOI: 10.1016/j.coldregions.2006.01.002

Edwards, Y., \& Redelius, P. (2003). Rheological effects of waxes in bitumen. Energy and Fuels, 17(3), 511-520. DOI: 10.1021/ef020202b

European Standard EN 12606-1 (2007). Bitumen and bituminous binders - determination of the paraffin wax content - part 1: method by distillation. European Committee for Standardization, EU.

Gorkem, I.C. (2014). Orta sıcaklıktaki asfalt karışımlarının performanslarının değerlendirilmesi. PhD. Thesis, Dokuz Eylul University, Izmir, TURKEY.

Gungor, A.G., \& Saglik, A. (2012). Evaluation of rutting performance of neat and modified binders using zero shear viscosity. 5th Eurasphalt \& Eurobitume Congress, Istanbul, TURKEY.

Lu, X., Kalman, B., \& Redelius, P. (2008). A new test method for determination of wax content in crude oils, residues and bitumens. Fuel, 87(8), 1543-1551. DOI:10.1016/j.fuel.2007.08.019

Lu, X., Langton, M., Olofsson, P., \& Redelius, P. (2005) .Wax morphology in bitumen. Journal of Materials Science, 40(8), 1893-1900. DOI: $10.1007 / \mathrm{s} 10853-005-1208-4$

Lu, X., \& Redelius, P. (2006). Compositional and structural characterization of waxes isolated \n from bitumens. American Chemical Society: Energy \& Fuels, 20(2), 653-660. DOI: 10.1021/ef0503414

Lu, X., \& Redelius, P. (2007). Effect of bitumen wax on asphalt mixture performance. Construction and Building Materials, 21(11), 1961-1970. DOI: 10.1016/j.conbuildmat.2006.05.048

Lyne, A., Wallqvist, V., \& Birgisson, B. (2013). Adhesive surface characteristics of bitumen binders investigated by Atomic Force Microscopy. Fuel, 113, 248-256. DOI: 10.1016/j.fuel.2013.05.042

Musser, B.J., \& Kilpatrick, P.K. (1998). Molecular characterization of wax isolated from a variety of crude oils. Energy Fuels, 12(4), 715-725.

Oner, J., \& Sengoz, B. (2017). Investigation of rheological effects of waxes on different bitumen sources. Road Materials and Pavement Design, 18(6), 1269-1287. DOI: 10.1080/14680629.2016.1209123

Santagata, E., Baglieri, O., Tsantilis, L., \& Dalmazzo D. (2012). Rheological characterization of bituminous binders modified with carbon nanotubes. Procedia Social and Behavioral Sciences, 53, 546-555. DOI: 10.1016/j.sbspro.2012.09.905 
Sengoz, B, Bagayogo, L., Oner, J., \& Topal, A. (2017). Investigation of rheological properties of transparent bitumen. Construction and Building Materials, 154, 1105-1111. DOI: 10.1016/j.conbuildmat.2017.07.239

Sengoz, B., \& Isikyakar, G. (2008). Evaluation of the properties and microstructure of SBS and EVA polymer modified bitumen. Construction Building Materials, 22(9), 1897-1905. DOI: 10.1016/j.conbuildmat.2007.07.013

Shenoy, A. (2008). Nonrecovered compliance from dynamic oscillatory test vis-à-vis nonrecovered compliance from multiple stress creep recovery test in the dynamic shear rheometer. International Journal of Pavement Engineering, 9(5), 329-341. DOI: 10.1080/102984307016350953

Shirini, B., \& Imaninasab, R. (2016). Performance evaluation of rubberized and SBS modified porous asphalt mixtures. Construction and Building Materials, 107, 165-171. DOI: 10.1016/j.conbuildmat.2016.01.006

Soenen, H., Besamusca, J., Fischer, H. R., Poulikakos, L. D., Planche, J., Das, P.K., Kringos, N., Grenfell, J.R. , Lu, X., \& Chailleux, E. (2013). Laboratory investigation of bitumen based on round robin DSC and AFM tests. Materials and Structures, 47(7), 1205-1220. DOI: 10.1617/s11527-0130123-4

Soudani, K., Cerezo, V., \& Haddani, S. (2016). Rheological characterization of bitumen modified with waste nitrile rubber (NBR). Construction and Building Materials, 104, 126-133. DOI: 10.1016/j.conbuildmat.2015.12.029

Subhy, A. (2017). Advanced analytical techniques in fatigue and rutting related characterisations of modified bitumen: Literature review. Construction and Building Materials, 156, 28-45. DOI: 10.1016/j.conbuildmat.2017.08.147

Topal, A., Kok, B.V., Kaya, D., Sengoz, B., Dokandari, P., \& Yilmaz, M. (2018). Investigation of the properties of warm mix asphalt involving organic additive. Turkish Journal of Science \& Technology, 13(1), 45-53.

Whiteoak, D., \& Read, J. M. (2003). The Shell bitumen handbook. Thomas Telford Services Ltd: London, UK.

Woolley, G. (1986). Polymer modified bitumen for extra value asphalt. Asphalt Technology, 38, 45-51.

Xiao, F., Hou, X., Amirkhanian, S., \& Kim, K.W. (2016). Superpave evaluation of higher RAP contents using WMA Technologies. Construction and Building Materials, 112, 1080-1087. DOI: 10.1016/j.conbuildmat.2016.03.024

Zhu, J., Birgisson, B., \& Kringos, N. (2014). Polymer modification of bitumen: Advances and challenges. European Polymer Journal, 54, 18-38. DOI: 10.1016/j.eurpolymj.2014.02.005 